\title{
A review of parent-professional partnerships and some new obligations and concerns arising from the introduction of the SEND Code of Practice 2015
}

\section{Abstract}

This article contributes a current review of literature about the challenges of productive parent-professional partnership working relating to children and young people with SEND. It also reports on an empirical project which explored early experiences of professionals working under the newly-statutory SEND Code of Practice 2015 and asks what new demands have emerged for SEND partnerships. Particular consideration is given to the language of choice and preference in the Code, the new focus on outcomes in the place of specified provision, and the problematic construction of compliant partners.

\section{Introduction}

This article has two aims. First, to contribute a current review of the debate in literature about the challenges of parent-partnership working relating to children and young people with SEND (special educational needs and disabilities). In my analysis, I particularly focus on the personal qualities of individual professionals and in-built structural limitations, rather than on organisational shortcomings or inadequate resources. I draw on literature from education, health and social care in line with the new requirement for professionals from these agencies to work together and with parents for the best interests of the child or young person. The second aim is to report on an empirical project which explored early experiences of professionals working under the newly-statutory SEND Code of Practice 2015 (DfE/DoH, 2015) and some new insights gained for the challenges and opportunities of parentpartnership working. Here I ask what new demands have emerged for SEND professionals and consider some ethical effects on partnerships with parents.

In this article, I use the generic term SEND professional when referring to personnel whose work is partly or wholly focused on meeting the needs of children with SEND. Class teachers, social workers, and health workers may have no particular prior interest or expertise in SEND, but their roles - sometimes as a consequence of policy changes - involve working with this group of learners to an increasingly greater extent. SEND professionals also include those with a particular focus on SEND, for example SENCOs (special educational needs co-ordinators) in charge of the strategic development of SEND provision in schools, SEN advisors and caseworkers who focus on the statutory assessment and review work at LA (local authority) level, SEN specialist teachers and support staff from LAs 
and schools providing front-line services, and some health professionals who have specialised in this area.

The SEND CoP (Code of Practice) 2015 (most explicitly stated in the preceding Support and Aspiration consultation document; DfE, 2011) identifies defensive and unresponsive professionals in local government, and front-line professionals in schools who are overwhelmed by bureaucratic complexities, as undermining the expectations of parents and the wider public. The stated aim of the reform is, therefore, to "challenge any dogma, delay or professional interests which might hold children and young people with SEND back" (DfE, 2013, p.4) and with this suggests that professionals working in the field may be directly responsible for the reported lack of progress (Lamb, 2009) that has been made in realising effective partnership working. The evident belief that "professionals operate against the public interest to further their own purposes" (Fisher, 2011, p.462) logically dictates the introduction of a statutory code which narrows and prescribes local professional action as a remedy. It may limit professional autonomy and marginalise locally elected democratic systems (Lamb, 2011) in favour of policies informed by market principles and new forms of accountabilities and ethics (Cribb \& Ball, 2005). My empirical work set out to explore these new forms of accountabilities and ethics in relation to parent-partnership working.

\section{A brief history of parent-partnership working}

Parental involvement in education has been championed in more recent times as a way of improving educational outcomes for children (Deforges \& Abouchaar, 2003; Jeynes, 2012), but has been a crucial component in SEND policy ever since the Warnock Report (DES, 1978) coined the phrase 'parents as partners'. A somewhat dated review of parentprofessional partnerships across education, health and social care (Macpherson, 1993) acknowledges that the field of SEN has been at the "forefront of debating partnerships and that the strongest ideals and most forceful rhetoric on partnership with parents comes from there" (p.67). Interestingly, the review identifies the motivation for parent-partnerships as the quest for democratic participation in society, rather than the more recent emphasis on marketisation and best outcomes, and suggests that the "ideology of individual consumer choice is likely to mean little" (p.72) for parents with children with SEN. The review argues that traditional discourses of professionalism and bureaucracy were challenged by the arrival of 'new' professionals (for example Educational Psychologists) and rights-based parentpartnership organisations from the 1970s onwards. In the 1980s, parents were re-positioned as drivers of the market, and in the managerialist regimes of the 1990s parents consolidated their important position of influence, often with the help of voluntary sector organisations professing to represent their concerns. In the new millennium, parents were expected to 
exercise choice and were assumed to be able to do so as 'citizen-consumers', responsive to individual as well as more general local needs, suggesting a 'third way' between unrestrained individualism and restrictive social responsibility (Riddell \& Weedon, 2010).

The discourse of parental rights was further strengthened in the new millennium through the now defunct 2001 SEN Disability Act, the 2010 Equality Act and the recent Children and Families Act 2014. Parent-partnership working continued to be a key theme in government policy for children across departments and agencies, exemplified in The National Service Framework for Children, Young People and Maternity Services (DH/DfES, 2004), the Children's Plan (DCSF, 2007) and Aiming High (HM Treasury/DfES, 2007), as well as in initiatives such as Sure Start, the Early Support Programme, Children's Centres and Children's Trusts which all aimed to develop transdisciplinary approaches to SEND and presume the central importance of partnership working with parents (Russell, 2008). One important mechanism of these initiatives is the individualised purchasing of services with the aim of stimulating the local marketplace and personalise provision, a trend that is continuing with the personal budgets outlined in the SEND CoP 2015. It demonstrates that the main concern for parent-partnership working is no longer democratic participation, if it ever was.

\section{Models of partnership working}

Partnership working with parents is conceptualised and problematised in literature through a series of models which seek to illuminate shifting power relationships and offer solutions to the identified problems attributed to those unequal power allocations (Fredrickson \& Kline, 2009; Gates \& Atherton, 2007; Hodge \& Runswick-Cole, 2008; Hornby \& Lafaele, 2011; O'Connor, 2008). The expert model identifies parents as passive receivers of professional expertise; the transplant mode/ seeks to utilise parental engagement and conceives of them as implementers of received expertise and advice; and the informant model characterises parents as information providers to improve professional decision making. These models are all rejected in literature as incompatible with valued partnership working because of the implied deficit view of parents. The empowerment model seeks to enable mutual decision making but argues that professionals will need to and rightly should set the parameters, whereas the negotiating model envisages interchangeable roles and expects mutually agreed outcome decisions. The consumer model conceives of the parent as rational and informed decision-maker and the professional as a provider of information and supplier of the various provision options; and the dual-expert model (author's term) highlights an equal valuing of parental expertise about the child and a complementary technical expertise by the professional. This is the model most expressly articulated in the SEND CoP. 
Family-centred working from a health perspective has been described as "concerns and solutions [that] are identified in active collaboration with families where providers share complete information to help families to make informed decisions" (Goldfarb, 2010, p.94). This is also promoted by the Family Partnership Model (Davis \& Day, 2007) which casts professionals in the role of 'helpers' to ensure consensual decision-making in the best interests of the child. It relies on personal qualities, including respect, personal integrity, and humility, and promotes professional virtues rather than professional skills. Characteristics of this collaboration include a recognition that families are different and at continuously shifting places in their journey, as well as cultural considerations. Friswell (2014) distinguishes between mere participation (expressing views, taking part in debates) and co-production (all agree outcomes together, collective production of recommendations and actions), which is the new expectation for parent-partnership working under the SEND CoP.

\section{Power and complexity in parent-professional relationships}

Parent-partnerships are often portrayed as offering a welcome transformation of passive users dominated by paternalistic professionals to autonomous and self-creating subjects, and as ethically straightforward (Cribb \& Gewirtz, 2012). However, the demands placed on parents to select and evaluate provision, act as advocates for their children, and support achieving high academic standards are immense, and not all parents can meet these demands: "Choice options have shifted the burden from the collective shoulders of society onto the shoulders of parents" (Horvat \& Baught, 2015, p.9), although they don't necessarily have the required capacity, maybe because of insufficient time, or a lack of skills. Choice, therefore, is no longer ethically straightforward.

Whilst Riddell and Weedon (2010) portray hostile LA professionals, intent on protecting their hegemonic professionalism, and parents who suffer at their hands, others argue that the complex relationships between parents and professionals rather reveal "the fault-lines of some of the key tenets of contemporary social policy" (Macleod et al., 2012, p.1). Both parents and professionals are subjected to and often constricted by the performative demands made on them. Professionals, for example, are expected to continue to recommend and oversee individual deficit-model based interventions, rather than being enabled to focus on dismantling external barriers (Hodge \& Runswick-Cole, 2008), whilst parents are required to respond to newly-introduced expectations for strategic as well as case-related participation.

The easy dichotomy between the powerful professional and the powerless parent is also challenged by Todd and Higgins (1998) who conclude that professionals and parents are 
both powerful and powerless in different ways. They discuss that some parents' lacking cultural capital could be problematic for partnership working, but also highlight that the 'different but equal' discourse employed in partnership notions within education can be contrasted with uses outside education where partnership does not imply equality, but merely a joint endeavour. A discourse of equality between professionals and parents where the wellbeing and education of the parents' child is at stake obscures pre-existing power relations, because parents have a much greater investment in the partnership than professionals due to their long-term commitment to and affective involvement with their child. For Todd (2011), the key is for professionals to be "privilege cognisant", to identify and challenge normative practices if necessary, and "to step into the expert role when required, but to abandon it at other times" ( $p .80)$ in favour of being present and attentive to parental knowledge and wishes. This requires a significant level of discernment from individuals which draws on qualities beyond what current skills-based training and prescriptive guidance can offer to professionals.

\section{Two contrasting views on the continuing challenges in parent-partnerships}

Professionals often view parents as "well-intentioned but ill-equipped" (Macleod et al., 2012, p.9) in terms of their advocacy role. Whilst parents are credited with having the best interests of their child at heart, they are frequently seen as unable to meet those interests because of their own emotional needs, and as being either too limited (in terms of their personal, social or economic resources) or too demanding and unrealistic. Parents who seek to exercise choice - for example the choice to reject a placement that they feel is unsuitable - are often seen by professionals as uncooperative and their 'choice' as evidence of poor parenting, rather than as keeping their side of the bargain by being responsible and making a rational selection. Hodge \& Runswick-Cole (2008) also point to professionals focusing on "impairment effects and intra-family and intra-psychic aspects of parenting a SEND child" (p.640) to explain parental stress, rather than due to the challenge of maintaining positive relationships with professionals: Parents "feel that they are categorised as well-adjusted only if they acquiesce with professionals' decisions" (p.641). The traditional stages of grief model held by many professionals may have "directly contributed to dysfunctional" (Allred, 2015, p.48) parent-professional relationships as professionals habitually assume that SEND is seen as a tragedy by parents, with grief as the inevitable response. This, rather than justified dissatisfaction with services then explains parents' anger or disengagement in professionals' minds.

Many parents experience the SEND system as complicated and difficult to navigate, requiring a high level of active involvement without always having access to the relevant 
support infrastructure. Their confidence in the system is variable (HoC Education and Skills Committee, 2007; Lamb, 2009), but there is also evidence of largely positive views about educational provision by affected parents (Parsons et al., 2009). O'Connor (2008) finds that parents often resist the language of educational marketisation and are "unconvinced of the implied ownership and freedom to choose" (p.258), but rather comment on perceptions of professional gate-keeping. Parents' perceptions and levels of understanding about respective roles and responsibilities of schools and LAs are seen as major barriers to effective relationships between LA staff, school staff and parents. Demonstrating effective monitoring processes give parents the confidence that schools are making the necessary provisions, and effective SEND caseworkers are shown to be the most important resource LAs have for increasing parental satisfaction (White et al., 2010).

\section{Bureaucratic competence versus personal attributes}

The continued shortcomings of partnership working in the face of determined efforts by successive governments for improvement are often too easily ascribed to an absence of reciprocal and open communication and over-stretched resources. However, for O'Connor (2008) "bureaucratic competence cannot compensate for the personal qualities that create a genuine support system between parents and professionals", which leads her to conclude "that greater attention to personal attributes should be an elemental consideration of future recruitment" (p.265). Similarly, in Hodge \& Runswick-Cole's study (2008) parents were found to identify "open-mindedness, free thinking, and a willingness to take on board new perspectives" ( $p .645)$ by professionals as the most important indicators for effective partnership working with them. Paying attention to the personal qualities of SEND professionals may, therefore, be a more effective way of improving partnerships, rather than better guidelines, more efficient managerialist processes or wider parental choice.

Diverging views about the child's needs are known to be a key factor in generating conflict between professionals and parents (Tveit, 2014). However, both parents and professionals value the maintenance of positive relationships when conflicts arise and understand the need to remain in dialogue. Tveit's study demonstrates that professionals identify synergy effects from engaging in dialogue and welcome it, but they also insist that agreement must not be a prerequisite to dialogue. Whilst some partnership models imply equal roles for those engaged in dialogue, both professionals and parents, in fact, assign the role of moderator to the professional and expect the professional to remain rational and engaged (i.e. 'professional'), in contrast to parents who are allowed to remain silent or become emotional. Parent-professional dialogue which is assumed to be democratic and equal, but which has to be managed and moderated by the professional remains a paradox and the mixed 
messages it signals to parents and professionals alike goes some way towards explaining the continued difficulties in their partnerships.

\section{Intensified obligations for enabling parent-partnership working}

In this second part, I consider some of the intensified obligations for enabling parentpartnership working introduced with the SEND CoP 2015. I utlise data from a more farranging project which set out to listen and learn from the early experiences of SEND professionals collaborating under the statutory guidance of the new Code. The exploratory interpretive interview study draws on 16 in-depth semi-structured interviews conducted between October 2014 and February 2015, with participants occupying a range of professional roles relating to SEND from across education, health and social care agencies in 4 local authorities in England. Where the particular role of the participant is relevant, I indicate this in brackets and I use pseudonyms throughout.

The newly-strengthened "unchallenged mantra" (Hodge \& Runswick-Cole, 2008, p.637) of parent-partnership working is difficult for my participants to question and disrupt. They explore their duty for partnership working with parents and discuss the intensified obligation and necessary professional responses:

We know that parents' expectations have been raised, they want a better deal, they want more clarity, they want to have a say and a stake in decisions, certainly want more of a say about what happens to their children. So, the whole bar has been raised. (FLORA, SEN Improvement Officer)

I think their expectations are raised, I think any enablement of parents is a good thing. Social media enables parents more, they share more. Parents who are clued up are very clued up and we have to be more clued up, too. (OLGA, SEN Caseworker)

My participants welcome but are also troubled by intensified obligations for partnership working with parents. Their empathy for the challenges of parenting children with SEND ('Being the parent of a disabled child is hard...particularly a profoundly disabled child', OLGA) and their agreement with the moral necessity of engaging parents in partnership working makes it difficult for them to know how to respond to the conflicts arising from raised parental expectations.

\section{The language of choice and preference}

Whilst there is no doubt about the moral imperative for parental involvement, participants nevertheless problematise it. Lack of clarity about entitlement and procedures in the early 
stages of the new statutory arrangements affect parental confidence; lack of clarity around the language of choice and preference proofs particularly challenging for participants.

Parents have been led to believe that they will have greater choice (DfE, 2011, p.5) and yet, the SEND CoP 2015 merely states that parents have the right to express a preference (DfE/DoH, 2015, 9.79). This causes confusion and concern:

Parents now feel that they can dictate as to what it is that they want, which is fine, but it is the public's fund that you're spending, so you are constrained by the bureaucracy of what you can do and what you can't do. [...] You do have a choice, you can ask for this or that and yes, you do have a preference, but then you're told that you might not necessarily get it and that can be quite annoying. (LILLY, SEN Caseworker)

This annoyance results in disputes and sometimes allegations of professional incompetence or protectionism which professionals are frequently ill-equipped to address. Explanations for shortcomings include uneven power-relationships, excessive bureaucracy referred to by LILLY, incompatible working cultures and systems between agencies, weak leadership, conflicting demands arising from the policy layers of neoliberal policy making, and inadequate skills sets of practitioners (Barnes, 2008; Frost et al., 2005; Harris, 2005; Milbourne et al., 2003; Nind, 2002) but do not address insufficient capacity to articulate values and justifications for recommendations and actions more coherently. The Code's insistence that parents have the right to 'express a preference' without framing this right by moral enquiry which may argue for a denial of this preference on the grounds of distributive justice (rather than because of incompetent or uncaring professionals) leaves individuals such as LILLY exposed. In order to grow this capacity, professionals need to re-engage with moral enquiry as a tool to establish and articulate the basis for adopting particular values beyond individual preference (Murray, 2013).

Cribb and Entwistle (2011) advocate for an 'ethical middle way' to facilitate shared decision making in partnerships. This includes supporting individuals to "construct, check and prioritise preferences" (p.212) rather than presuming that these are a given based on rational consumer choice, but also the opportunity for professionals to question and challenge espoused preferences. An ethical middle way also involves an acknowledgement that demands are frequently made of professionals which they may not currently be able or willing to offer. These expectations may comprise significant levels of emotional literacy, sustained critical intellectual engagement, and an inclination to enter into more open-ended reciprocal relationships. Finding an ethical middle way relies on skills and virtues of individual professionals (as well as on increased capabilities of parents, already addressed 
in a number of ways through legislation) and these need to be actively developed and fostered by individuals and organisations.

\section{Same but different}

The SEND CoP 2015 treats parents as a homogenous group who are all assumed to be able to participate in the partnership project as private consumers and public citizens by simultaneously securing the best for their own child, and also at a commissioning level for all children. OLGA argues that most parents will not be able to act in this way:

I do understand that parents go into battle mode.... if they don't fight for their children, who is going to a lot of the time? (OLGA, SEN Caseworker)

This understanding leads her to accept that where relationships might be conflicted, there is nevertheless a justification for parents to act in this way, as it is seen as their primary moral duty to protect the interests of their own child. OLGA has alluded to a recognition that engaging in disagreements brought about by conflicting parental and professional interests is in fact built into the fabric of the parent-professional relationship. Constructing the presence of conflict as evidence for an inadequate professionalism (as Support and Aspiration has done) which needs to be regulated and contained by a prescriptive Code misses this point.

Some participants openly discuss the challenges of 'non-compliant' parental participants in the partnership process, which are not acknowledged and addressed in the Code:

You do have this really structured, legal process, but we are also working with people who are distressed by definition, really, and there is all sorts of other stuff driving things, and that tends to be different for each family or person. (GINA, SEN Caseworker)

NADIA also acknowledges that there are 'definitely different types of parents'. Whilst the new Code has failed to address the "changing and differing kinds of need" of parents who want "to be in a position to negotiate their own preferred identities" (Todd, 2011, p.66), participants recognise that greater involvement is not always liberating for parents:

The level of involvement expected from parents [...]. I have two parents in mind, where I can see some real difficulties to get any level of engagement from them... What if the parents don't even do that? Don't turn up? Don't turn up the next time you set the meeting? That sort of undermines the success of the process for that child. We do have parents who don't show up for reviews and it is not always because they are not interested or involved, sometimes it is their lives are just too complicated. (CARMEN, SEN Caseworker) 
OLGA also knows of some parents who simply don't follow the script: 'That's their comment, they don't want to be involved'. She feels particularly troubled because she doesn't want to feel co-opted into engineering this compliance from parents.

\section{From provision to outcomes}

The new Code introduces a very explicit shift from agreeing and securing specialist provision in support of meeting certain targets, to focusing on aspirational outcomes. These outcomes need to be co-produced with families and are documented in Section E of the new EHC Plan in a way that makes the impact of provision measurable, preferably in the form of SMART targets. There is significant unease around EHC Plan outcomes amongst my participants, often because of not fully understanding what is meant by outcomes, how they differ from SMART targets and who should formulate either of them. Educationalists credit their social work colleagues with prior experience and a greater ability to design SMART targets but doubt that SMART targets exemplified in Child in Need Plans are truly child-centred and coproduced with parents. Rather than adopting this existing approach from partners, some participants are grappling with developing practices which can incorporate the moral imperatives of both child-centeredness and of co-production, because this is where the real benefit would lie.

Unease is also expressed about how the focus on future outcomes affects partnerships with parents:

Parents don't think future-wise, the Statement never forced them to do that. Now, they're having to think, 'I might not be here one day, so what does this mean?', and that is a really stark conversation. (LILLY, SEN Caseworker)

Parents are expected to engage in the co-production of aspirational outcomes at a level that may be extremely difficult to do so emotionally, and professionals need to become sensitised to this, as they may otherwise be ill-equipped to lead and contain those conversations.

Outcomes, as envisaged in the new Code, hold contradictory beneficial goals. There are clear links to an extrinsically driven "value agenda" (Hammersley-Fletcher, 2015, p.198) which compels SEND professionals to competently negotiate and articulate ambitious outcomes, and then to be accountable for meeting those in the form of achieved SMART targets; professionals here need to demonstrate their value to their organisation and in their partnerships. The temptation to formulate more modest outcomes which are more likely to be realised, rather than ambitious ones which could serve the child better, but may also leave a professional exposed, was discussed and highlighted as potentially unethical by some participants. 
A re-focusing from specialist provision, where the attention is on the professional, to outcomes for the child also establishes clear links to the intrinsic values of being childcentred and of focusing on wellbeing and realised capabilities (Terzi, 2008). Sometimes, those particular outcomes might be valued by both parents and professionals, but cannot be easily measured. PEETA, a health professional, talks in this context about an intervention with a child where she contributed her 'expertise in complexity and uncertainty', but where the outcome was not measurable in terms of SMART targets, and therefore 'didn't count'. This "underlying conflict between values and value is played out daily and places a heavy emotional demand" (Hammersley-Fletcher, 2015, p.212) on professionals, and also on productive parent-partnership working.

\section{Communication 'between the lines' and 'behind the scenes'}

Professionals walk a tightrope between illustrating that they have already secured relevant provision and interventions for children with SEND, and have in fact done a good job but will nevertheless need additional resources to maintain the same level of support; and focusing on the needs and problems of the child which release additional funding but might also suggest that they have simply not provided competently, or are unsympathetic to parental hopes and aspirations:

Sometimes l've actually had to say to parents, 'Look, I know this sounds awful, but if we seem far too positive and are so focused on how wonderful it is that they've made good progress, the Panel might say, 'Oh, this child's all right then'. So what we need to be actually pointing out are the difficulties and the needs'. It's not to do with exaggerating, ... but you have to say, 'Look, if this is not something that's a regular thing...', and you just hope that the SEN people can then read between the lines. (ELLA, SENCO)

Whilst maybe well-intended, this way of working excludes parents from being partners in a transparent way, as it is professional discourse that is communicated 'between the lines'. It also results in game-playing which detracts from true collaboration.

Partnership literature acknowledges complexity as a given that needs to be worked with, although there is usually an expectation that negotiating this complexity should be done "behind the scenes" (DH, 2001, p.12) rather than in front of parents. My participants generally go along with this advice and agree, sometimes at great cost to themselves, to be 'the face of the authority' but also to 'make sure people know what my view is internally'. Some parents experience the united front of professionals as a powerful conspiracy; they would rather be involved in discussing the complexities of their child's case, including where this reveals professional disagreements and uncertainty (Hodge \& Runswick-Cole, 2008). 
The authors conclude that "parents are much more able to manage uncertainty than professionals realise" (p.642). My participants' clear recognition that there are 'definitely different types of parents' and that 'each family is different' could certainly lead them to involve at least some parents in the complexities and uncertainties of a particular case. However, a prescriptive Code that has explicitly set out to address and 'fix' an underperforming professionalism which has antagonised parents (DfE, 2011, p.2) may not be able to embolden professionals to test this unknown and uncertain territory.

\section{Conclusion}

My participants don't challenge the intentions of policy makers to empower parents and enable their greater participation, although they admit to conflicting feelings of empathy and sometimes exasperation. Some hint at a recognition that parents as 'empowered' service users, as much as professionals, are expected to follow prescriptive normative scripts and express doubt that the Code constitutes real empowerment rather than simply a shift from the compliant parent to the compliant partner (Cribb \& Gewirtz, 2012). Participants recognise the contradictions around expectations that parents share responsibility for exercising personal judgements ('they want to have a say and a stake in decisions'); work collaboratively ('you do have this really structured, legal process, but we are also working with people who are distressed by definition'; 'if they don't fight for their children, who is going to a lot of the time?'); and follow prescriptive processes ('we do have parents who don't show up for reviews and it is not always because they are not interested or involved, sometimes their lives are just too complicated'). The presumption that professionals will participate in engineering this parental compliance and portray it as empowerment troubles some participants most.

The moral principle of autonomy implies that "parents have a moral right, not a mandatory duty, to know and choose" (Fox, 2015, p.368). Professionals who uphold this parental autonomy may simply be unwilling to 'deliver' partnership working in just the way performative legislation envisages and may in this sense be conscientious objectors to engineering partnerships, rather than match Hudson's (2005) assessment that those who are not minded to engage in partnership working will not do so whatever the legislative requirements are. Whilst my study has not interviewed parents directly, it may well be the case that the new expectation that parents engage at a personal case-level as well as a commissioning-level places unexplored and unintended ethical demands on individuals who are already disproportionately challenged by their circumstances, which some professionals recognise, even if it is not acknowledged in the Code. 


\section{References}

Allred, K. W. (2014) 'Engaging parents of students with disabilities: Moving beyond the grief model', Improving Schools, 18(1), 46-55.

Barnes, P. (2008) 'Multi-agency working: What are the perspectives of SENCOs and parents regarding its development and implementation?'. British Journal of Special Education, 35(4), 230-240.

Cribb, A. \& Ball, S. (2005) 'Toward an ethical audit of the privatisation of education', British Journal of Educational Studies, 53(2), 115-128.

Cribb, A. \& Entwistle, V. (2011) 'Shared decision making: Trade-offs between narrower and broader conceptions', Health Expectations, 14, 210-219.

Cribb, A. \& Gewirtz, S. (2012) 'New welfare ethics and the remaking of moral identities in an era of user involvement', Globalisation, Societies and Education, 10(4), 507-517.

Davis, H. \& Day, C. (2007) Current family partnership model. Retrieved 2 February, 2016, from

http://www.cpcs.org.uk/uploads/downloads/family\%20partnership\%20model/Current\%20FP M\%20Framework.pdf

DCSF (Department for Children, Schools and Families) (2007) The children's plan: Building brighter futures. London: HMSO.

Desforges, C. \& Abouchaar, A. (2003) The impact of parental involvement, parental support and family education on pupil achievements and adjustment: A literature review. Nottingham: DfES Publications.

DfE (Department for Education) (2011) Support and aspiration: A new approach to special needs and disability - a consultation. London: HMSO.

DfE (Department for Education) (2013) Children and Families Bill 2013: Contextual information and responses to pre-legislative scrutiny. Retrieved February 24, 2016, from https://www.gov.uk/government/uploads/system/uploads/attachment_data/file/219658/Childr en_20and_20Families_20Bill_202013.pdf

DfE/DoH (Department for Education/Department of Health) (2015) Special educational needs and disability Code of Practice: 0 to 25 Years. Retrieved 30 July, 2015, from https://www.gov.uk/government/uploads/system/uploads/attachment_data/file/398815/SEND _Code_of_Practice_January_2015.pdf

DH (Department of Health) (2001) Valuing people. Retrieved 20 May, 2016, from https://www.gov.uk/government/uploads/system/uploads/attachment_data/file/250877/5086. pdf

DH/DfES (Department of Health/Department for Education and Skills) (2004) The national service framework for children, young people and maternity services. Retrieved 16 February, 2016, from

https://www.gov.uk/government/uploads/system/uploads/attachment_data/file/199952/Nation al_Service_Framework_for_Children_Young_People_and_Maternity_Services__Core_Standards.pdf 
Fisher, T (2011) 'Considering the big picture: How significant are policy initiatives?', Educational Review, 63(4), 455-465.

Fox, M. (2015) 'What sort of person ought I to be?' - Repositioning EPs in light of the Children and Families Bill', Educational Psychology in Practice, 31(4), 382-396.

Fredrickson, N. \& Kline, T. (2009) Special educational needs, inclusion and diversity $\left(2^{\text {nd }}\right.$ ed.). Maidenhead: Open University Press/McGraw-Hill.

Friswell, J. (2014) Working with families and keeping parents and carers engaged in meeting the needs of pupils with SEND. Retrieved 16 February, 2016 from www.rnlcom.com/wpcontent/uploads/2014/03/Jane-Friswell-PPoint.pptx

Frost, N., Robinson, M. \& Anning, A. (2005) 'Social workers in multidisciplinary teams: Issues and dilemmas for professional practice', Child and Family Social Work, 10, 187-196.

Gates, B. \& Atherton, H. (2007) Learning disabilities: Towards inclusion. Edinburgh: Elsevier/Churchill Livingstone.

Goldfarb, F. D. (2010) 'Partnering with professionals: Family-centred care from the parent perspective', Journal of Family Social Work, 13(2), 91-99.

Hammersley-Fletcher, L. (2015) 'Value(s)-driven decision-making: The ethics work of English headteachers within discourses of constraint', Educational Management Administration \& Leadership, 43(2), 198-213.

Harris, S. (2005) 'Professionals, partnerships and learning in changing times', International Studies in Sociology of Education, 15(1), 71-86.

HM Treasury/DfES (Department for Education and Skills) (2007) Aiming high for disabled children. Retrieved September 28, 2015, from

http://webarchive.nationalarchives.gov.uk/20130401151715/http://www.education.gov.uk/pu blications/eOrderingDownload/PU213.pdf

Hodge, N. \& Runswick-Cole, K. (2008) 'Problematising parent-professional partnerships in education', Disability and Society, 23(6), 637-647.

Hornby, G. \& Lafaele, R. (2011) 'Barriers to parental involvement in education: An explanatory model', Educational Review, 63(1), 37-52.

Horvat, E. M. \& Baught, D. (2015) 'Not all parents make the grade in today's schools', Phi Delta Kappan, 96(7), 8-13.

HoC (House of Commons) Education and Skills Select Committee (2007) Special educational needs: Assessment and funding. Tenth report of session 2006-2007. Retrieved May 30, 2014, from http://www.publications.parliament.uk/pa/cm200607/cmselect/cmeduski/1077/1077.pdf

Hudson, B. (2005) 'Information sharing and children's services reform in England: Can legislation change practice?', Journal of Interprofessional Care, 19(6), 537-546.

Jeynes, W. (2012) 'A meta-analysis of the efficacy of different types of parental involvement programs for urban students', Urban Education, 47(4), 706-742. 
Lamb, B. (2009) The Lamb enquiry: Special educational needs and parental confidence. Retrieved August 3, 2015, from

http://webarchive.nationalarchives.gov.uk/20100202100434/http://dcsf.gov.uk/lambinquiry/do wnloads/8553-lamb-inquiry.pdf

Lamb, B. (2011) 'Support and aspiration: Cultural revolution or pragmatic evolution?', Journal of Research in Special Educational Needs, 12, 107-121.

Macleod, G., Pirrie, A., McCluskey, G. \& Cullen, M. S. (2012) 'Parents of excluded pupils: Customers, partners, problems?', Educational Review, 1(1), 1-15.

Macpherson, A. (1993) 'Parent-professional partnership: A review and discussion of issues', Early Child Development and Care, 86(1), 61-77.

Milbourne, L., Macrae, S. \& Maguire, M. (2003) 'Collaborative solutions or new policy problems: Exploring multi-agency partnerships in education and health work', Journal of Educational Policy, 18(1), 19-35.

Murray, D. (2013) Professional school leadership: Dealing with dilemmas. London: Dunedin Academic Press.

O'Connor, U. (2008) 'Meeting in the middle? A study of parent-professional partnerships', European Journal of Special Needs Education, 23(3), 253-268.

Parsons, S., Lewis, A., Davison, I., Ellinis, J. \& Robertson, C. (2009) 'Satisfaction with educational provision for children with SEN or disabilities: A national postal survey of the views of parents in Great Britain', Educational Review, 61(1), 19-47.

Riddell, S. \& Weedon E. (2010) 'Reforming special education in Scotland: Tensions between discourses of professionalism and rights', Cambridge Journal of Education, 40(2), 113-130.

Russell, P. (2008) 'Building brighter futures for all our children' - a new focus on families as partners and change agents in the care and development of children with disabilities or special educational needs', Support for Learning, 23, 104-112.

Terzi, L. (2008) Justice and equality in education: A capability perspective on disability and special educational needs. London: Bloomsbury.

Todd, E. S. \& Higgins, S. (1998) 'Powerlessness in professional and parent partnerships', British Journal of Sociology of Education, 19(2), 227-236.

Todd, L. (2011) 'Multi-agency working and disabled children and young people: From what works to active becoming'. In S. Haines and D. Ruebain (Eds.), Education, disability and social policy (pp.65-87). Bristol: Policy Publications Ltd.

Tveit, A. D. (2014) 'Researching teachers' and parents' perceptions of dialogue', International Journal of Inclusive Education, 18 (8), 823-835.

White, R., Macleod, S., Jeffes, J. \& Atkinson, M. (2010) Local authorities' experiences of improving parental confidence in the special educational needs process. Retrieved May 10 , 2014 from https://www.nfer.ac.uk/publications/LAM01/LAM01.pdf 